\title{
SERVICE LIFE EVALUATION EXPERIENCE FOR EXISTING RAILWAY STEEL BRIDGE IN CHINA
}

\author{
Xiao-yan Tao* and Yu-ling Zhang \\ Bridge Section, China Academy of Railway Sciences, No. 2 Daliushu Road, Xiwai, Beijing, 100081, China \\ *(Corresponding author: E-mail: taoxy1994@163.com)
}

\begin{abstract}
It is well-known that the stress range spectrum is the key factor to the service life evaluation of existing railway steel bridge based on the damage accumulation theory. Taking two typical existing railway steel bridges in China as examples, two technical methods were introduced to determine the operation stress range spectra during the service condition in this paper, and then the service life was evaluated. One is named as Test Method and another is named as Load Simulation Method. Comparing the process and the workload, pros and cons of two technical methods were studied. The actual load effects can be considered in Test Method, such as dynamic effect, acceleration effect, etc. But potential limitation of Test Method is too dependent on the test data, and the deviation of selecting the test position will affect the assessment result. Load Simulation Method can be used to calculate the fatigue stress history of any position, thus avoiding potential limitation of Test Method, but it must be based on adequate statistical information and large amount of calculation. In order to improve the accuracy of assessment results by these two methods in the future, some new research works are proposed at the end of the paper.
\end{abstract}

Keywords: Railway steel bridge, Damage accumulation, Fatigue life evaluation, Stress range spectrum, Stress history

DOI: $10.18057 /$ IJASC.2015.11.3.8

\section{INTRODUCTION}

Steel bridges are widely used in railway infrastructure in China, which includes 6550 steel girder bridges by the end of 2010. Most of the steel railway bridges are steel plate girder bridges or steel truss girder bridges, and box girder bridges have begun to be used in railway bridges in recent years. There are 4547 steel girder bridges that have serviced for more than 50 years under railway traffic, including 3884 steel plate girder bridges and 484 steel truss girder bridges. More data can be found in statistical information $[1,2]$.

Along with the growth of the traffic volume and the traffic flow rate coupled with environment actions [3], it is the matter of concern for the bridge engineers how to evaluate the safety and the fatigue remaining life of the existing steel bridges, and it is also an important research topic in current railway bridge professions.

There are generally two following steps to analyze the fatigue life of railway steel bridges based on damage accumulation theory in China. First, determine the operation stress range spectrum in detail during the bridge service condition by simulating the stress range spectrum in various historical periods and predict the stress range spectrum in future, which are shown in Figure 1. Next, calculate the damage in each operation period based on the Palmgren-Miner rule and S-N curve, which is shown in Figure 2, and then the remaining life of the bridge is determine by the following criteria(see Eq.(1)). More information can be found in the researches of Pan [4, 5] and Shi [6, 7].

$D=\sum \frac{n_{i}}{N_{i}}=\frac{n_{1}}{N_{1}}+\frac{n_{2}}{N_{2}}+\cdots+\frac{n_{n}}{N_{n}} \leq 1$ 


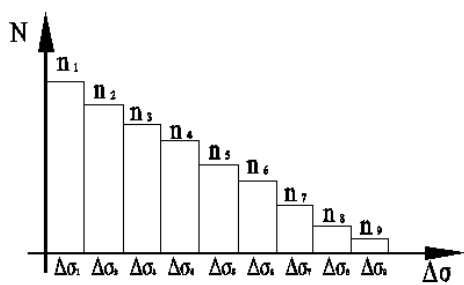

Figure 1. The Operation Stress Range Spectrum

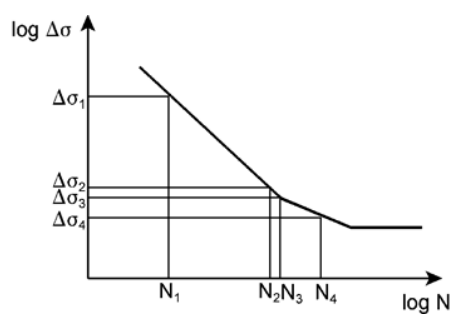

Figure 2. S-N Curve

Railway steel bridge researchers always calculate the damage by the same research method mentioned above in China. But to determine the operation stress range spectrum, there are two technical methods at present. One is named as Test Method, the other is named as Load Simulation Method. Taking two typical existing railway steel bridges in China as examples, two technical methods are introduced as below, and the service life is evaluated.

\section{TWO METHODS FOR DETERMINING THE OPERATION STRESS RANGE SPECTRUM}

How to determine the operation stress range spectrum during the service condition is an important step during the course of the bridge fatigue assessment. Stress range spectrum can be determined by the following two methods.

\subsection{Test Method}

The stress history can be recorded by installing the strain gauges to the position of the bridge where the fatigue failure is more prone to happen. Then, simulate the stress range spectrum in various historical operation periods and forecast the stress range spectrum in future through the short-term stress spectrum in test period together with the traffic volume. Because actual test period is extremely shorter than the bridge service life and many influencing factors are impossible to be included, the stress range and their numbers of cycles which are determined by rainflow method in each operation period need to be corrected.

The stress range can be corrected as follows (see Eq.(2)).

$\left[\sigma_{f}\right]=k_{1} k_{2} k_{3} k_{4} k_{5}\left[\begin{array}{c}\sigma_{1} \\ \sigma_{2} \\ \vdots \\ \sigma_{n}\end{array}\right]$

Where $\left[\begin{array}{c}\sigma_{1} \\ \sigma_{2} \\ \vdots \\ \sigma_{n}\end{array}\right]$ is stress range related to a stress spectrum in a short test period; $k_{1}$ is the adjustment factor considering eccentricity of vertical load; $k_{2}$ is the adjustment factor of considering some special heavy train which do not operate in short-term test period; $k_{3}$ is the stress conversion factor between the evaluated detail and the actual test detail; $k_{4}$ is the adjustment factor of considering the difference of locomotive and vehicle types between the test period and the service period (If the stress history is directly corrected by referencing to pervious similar test or simulating calculation, $k_{4}$ is taken as 1.0.); $k_{5}$ is the adjustment factor of considering secondary stress. 
Their numbers of cycles can be corrected as Eq. (3)

$\left[n_{f}\right]=\alpha_{1} \alpha_{2} \alpha_{3} \alpha_{4}\left[\begin{array}{c}n_{1} \\ n_{2} \\ \vdots \\ n_{n}\end{array}\right]$

Where $\left[\begin{array}{c}n_{1} \\ n_{2} \\ \vdots \\ n_{n}\end{array}\right]$ is the number of stress cycle related to a stress spectrum in a short test period; $\alpha_{1}$ is the adjustment factor of considering the different daily traffic volume within one month; $\alpha_{2}$ is the adjustment factor of considering the different monthly traffic volume within one year; $\alpha_{3}$ is the adjustment factor of considering the different yearly traffic volume during entire service period; $\alpha_{4}$ is the adjustment factor corresponding to vehicles gross weight change in every train, which closely linked to the locomotive traction gross weight, and is given in Table 1.

Table 1. The Locomotive Traction Gross Weight and $\alpha_{4}$

\begin{tabular}{cccc}
\hline Locomotive & $\begin{array}{c}\text { Steam } \\
\text { locomotive }\end{array}$ & Diesel locomotive & $\begin{array}{c}\text { Electric } \\
\text { locomotive }\end{array}$ \\
\hline Gross Weight (t) & 2000 & 3500 & 5000 \\
$\alpha_{4}$ & 0.57 & 1.00 & 1.43 \\
\hline
\end{tabular}

After correcting the stress range and their numbers of cycles in each operation period, the operation stress range spectrum during bridge service condition can be determined.

\subsection{Load Simulation Method}

Firstly, analyze the vehicles marshalling in a train and the train formation within one day. Secondly, simulate the typical operation train in every operation period on the basis of the statistics data. Thirdly, adjust the various factors of the typical operation train by matching its action effect to the actual train effect. Finally, calculate the stress history induced by the typical operation train and determine the operation stress range spectrum.

\subsubsection{Typical operation train Determination}

In every operation period, the typical operation train for fatigue research is determined by average weight of different type locomotives and vehicles, the vehicle numbers, and the vehicle carrying capacities. The types of the locomotives or the vehicles are decided by the $P$ values, which can be calculated as Eq. (4).

$$
P=\frac{p_{i}}{\Sigma p_{i}}
$$

Where $p_{i}$ is the number of specific type of locomotives or vehicles; $\Sigma p_{i}$ is the total number of locomotives or vehicles.

Vehicle number of every train shall be determined according to Eq. (5) 


$$
N=\frac{\Sigma n_{i} k_{i}}{\Sigma k_{i}}
$$

Where $n_{i}$ is the vehicle number of a train; $\Sigma k_{i}$ is the number of trains passing through.

Since the vehicle carrying capacities are stochastic and complex, they are divided into several grades for simplification. Carrying capacities in each grade can be calculated by Eq. (6).

$$
W=\frac{\Sigma p_{i} w_{i}}{\Sigma p_{i}}
$$

Where $p_{i}$ is vehicle number of specific carrying capacity in one grade; $w_{i}$ is the average value of vehicle carrying capacity; $\Sigma p_{i}$ is the total vehicle number in one grade.

The typical operation train can be obtained on the basis of the above calculation. Then the train operation frequency can be determined according to the traffic volume.

\subsubsection{Theoretical load effect Correction for fatigue research}

Stress history of the typical operation train can be calculated by theoretical simulation. Stress ranges and their numbers of cycles can be determined by rainflow method. In order to match theoretical effects to the actual train effects, stress range shall be adjusted by Eq. (7).

$\left[\sigma_{f}\right]=\delta_{1} \delta_{2}\left[\begin{array}{c}\sigma_{1} \\ \sigma_{2} \\ \vdots \\ \sigma_{n}\end{array}\right]$

Where $\delta_{1}$ is the adjustment factor considering dynamic effect, and can be referenced according to Eq. (8).

$\delta_{1}=1+\frac{14}{40+L}$

Where $L$ is the span length (m). More information about dynamic effect can be found in [8]; $\delta_{2}$ is the adjustment factor considering the random arrangement of the vehicles of a train; $\delta_{1} \delta_{2}$ can also be experientially obtained by analyzing the theoretical load effect and the tested train load effect. Same to Test Method, after correcting the stress range in every operation period, the operation stress range spectrum during bridge service condition can be determined.

There are two examples below to illustrate and compare these two technical methods further.

\section{EXAMPLE ONE: EVALUATION OF A STEEL PLATE GIRDER BRIDGE}

The first example is a riveted steel plate girder bridge with $32 \mathrm{~m}$ span, which is under a single track railway. This bridge was built in 1911, and located in a branch railway. The steel plate girder is mainly composed of main beams, floor beams and stringers. The main beams and floor beams were riveted by the angle steel and the steel plate and the stringers were hot rolled I-shape section. Webs of two main beams were riveted by ten steel plates, and the stiffeners were arranged on the both 
sides of main beam webs.

Before 1994, the traction engines were steam locomotives, but now they are DF4 diesel locomotives. About ten trains pass through the bridge every day, and the trains are primarily coal trains and a few of passenger trains. After 2011, the traction engines are SS4 electric locomotives. The bridge operation state is good, and its scenery can be seen in Figure 3.

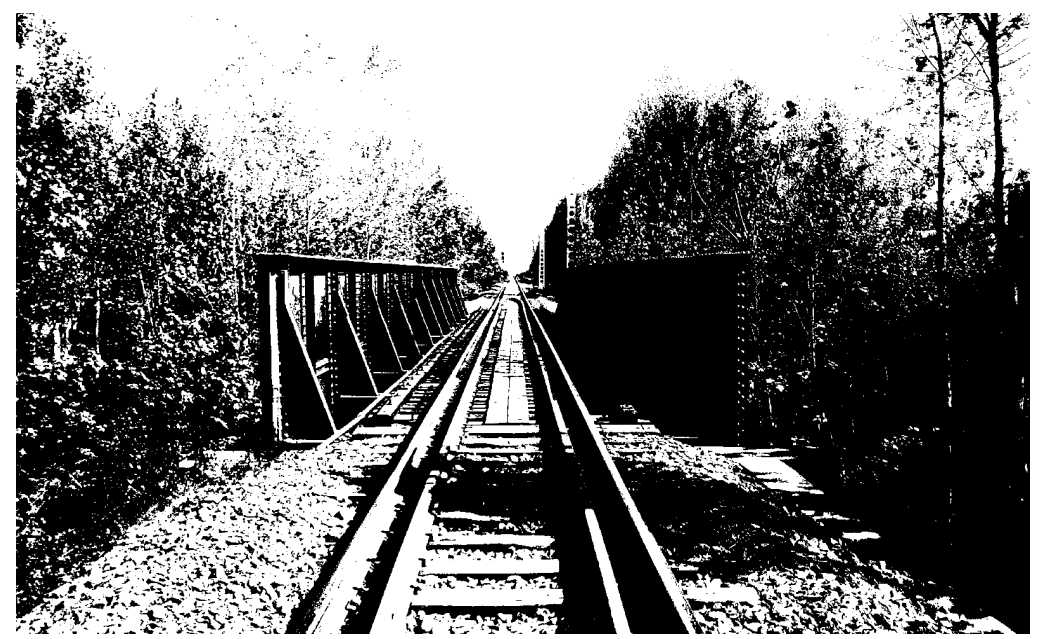

Figure 3. Steel Plate Girder Bridge

Main beams, floor beams and stringers are the critical members of the bridge to bear the train load. The strain gauges were placed in their mid-span sections. According to the results of structural stress analysis, the control details of main beams and floor beams are the cross sections which were weaken by rivet holes. Because the stringer is the hot rolled I-shaped steel, the control detail is the base metal section in mid-span. According to "Railway Bridge Examination Standard (2004)" [9], the $\mathrm{S}-\mathrm{N}$ curve of the main beam and the floor beam is $\lg N=13.14-3.5 \lg \Delta \sigma$, and the S-N curve of the stringer is $\lg N=13.30-3.5 \lg \Delta \sigma$. The fatigue damage and the fatigue remaining life of this bridge were evaluated by the two technical methods mentioned above.

The main adjustment factors of Test Method are listed in Table 2, and the operation stress range spectrums determined by Test Method are shown in Figure 4. According to the test result of eccentricity, $k_{1}$ is taken as 1.02. $k_{2}$ can be determined by train formation during the service period. The strain gauges of the main beams were placed in the gross section, so $k_{3}$ for the main beam is the area ratio of gross and net section. The strain gauges of the floor beams were placed in the net section, so $k_{3}$ for the floor beam is taken as 1.0. The stringers were the hot rolled I-shaped steel, so $k_{3}$ for the stringer is also taken as 1.0. The influence of the locomotive and vehicle types is considered by directly correcting the stress history according to pervious test before 1994 and by simulating calculation after 2011, so $k_{4}$ is taken as 1.0 . The influence of secondary stress can be ignored in the bridge, so $k_{5}$ is taken as 1.0. The daily traffic volume in one month is almost the same, so $\alpha_{1}$ is taken as 1.0. The value of $\alpha_{2}$ is the traffic volume ratio of the testing month and the annual monthly average, so $\alpha_{2}$ can be easily determined. The value of $\alpha_{3}$ can be determined by the forecasted traffic volume in future and listed in Table 2 . The value of $\alpha_{4}$ is given in Table 1 and also listed in Table 2 below. 
Table 2. Values of Adjustment Factor in Test Method

\begin{tabular}{cccccccc}
\hline \multirow{2}{*}{ Time } & Members & $k_{1}$ & $k_{2}$ & $k_{3}$ & $\alpha_{2}$ & $\alpha_{3}$ & $\alpha_{4}$ \\
\hline \multirow{3}{*}{$1911-1994$} & Main beam & 1.020 & 1.005 & 1.110 & 0.912 & 1.000 & 0.570 \\
& Floor beam & 1.000 & 1.005 & 1.000 & 0.912 & 1.000 & 0.570 \\
& Stringer & 1.020 & 1.005 & 1.000 & 0.912 & 1.000 & 0.570 \\
& Main beam & 1.020 & 1.005 & 1.110 & 0.912 & 1.000 & 1.000 \\
$1995-2011$ & Floor beam & 1.000 & 1.005 & 1.000 & 0.912 & 1.000 & 1.000 \\
& Stringer & 1.020 & 1.005 & 1.000 & 0.912 & 1.000 & 1.000 \\
& Main beam & 1.020 & 1.005 & 1.110 & 0.912 & 1.590 & 1.430 \\
\multirow{2}{*}{$2021-2020$} & Floor beam & 1.000 & 1.005 & 1.000 & 0.912 & 1.590 & 1.430 \\
& Stringer & 1.020 & 1.005 & 1.000 & 0.912 & 1.590 & 1.430 \\
& Main beam & 1.020 & 1.005 & 1.110 & 0.912 & 2.260 & 1.430 \\
& Floor beam & 1.000 & 1.005 & 1.000 & 0.912 & 2.260 & 1.430 \\
& Stringer & 1.020 & 1.005 & 1.000 & 0.912 & 2.260 & 1.430 \\
\hline
\end{tabular}

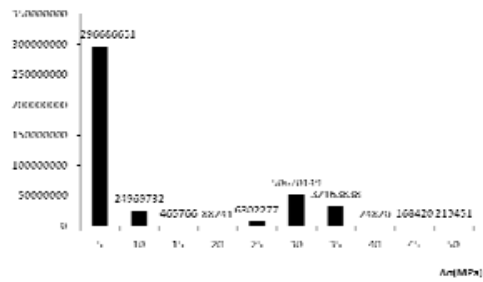

(a)Main beam

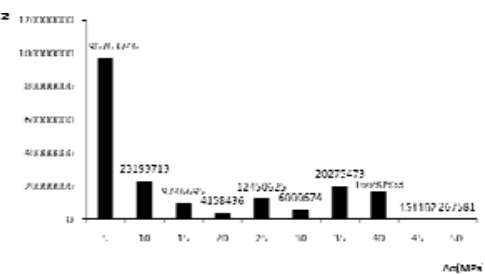

(b)Floorbeam

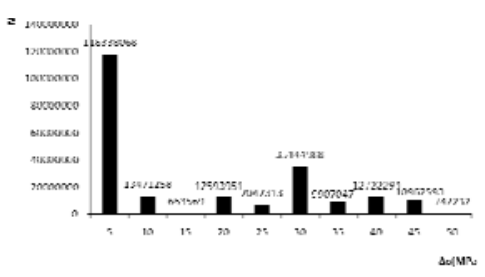

(c)Stringer

Figure 4. The Operation Stress Range Spectrums Determined by Test Method

The typical operation trains of Load Simulation Method are listed in Table 3.

Table 3. Typical Operation Trains of Load Simulation Method

\begin{tabular}{cccccccccccccc}
\hline & \multicolumn{1}{c}{ The vehicles carrying capacity $(\mathrm{t})$} \\
Year & Vehicle & \multicolumn{3}{c}{30} & 35 & 45 & 50 & 55 & 60 & 65 & Operation \\
& number & 0 & $\sim$ & $\sim$ & $\sim$ & $\sim$ & $\sim$ & $\sim$ & $\sim$ & Passenger & Locomotive \\
& & & 35 & 40 & 50 & 55 & 60 & 65 & 70 & & \\
\hline $1911-1994$ & 50 & 8 & 4 & 5 & 2 & 3 & 8 & 12 & 8 & 9 & - & QJ \\
$1995-2011$ & 50 & 8 & 4 & 5 & 2 & 3 & 8 & 12 & 8 & 9 & - & DF4 \\
$2012-2020$ & 50 & 8 & 4 & 5 & 2 & 3 & 8 & 12 & 8 & 13 & 1 & SS4/SS7E \\
$2021-$ & 50 & 8 & 4 & 5 & 2 & 3 & 8 & 12 & 8 & 20 & 2 & SS4/SS7E \\
\hline
\end{tabular}

The value of $\delta_{1}$ can be calculated according the formula given above. The random arrangement of the vehicles in a train can be ignored in the bridge, so $\delta_{2}$ is taken as 1.0. Values of $\delta_{1}$ and $\delta_{2}$ are given in Table 4.

Table 4. Values of $\delta_{1}$ and $\delta_{2}$

\begin{tabular}{cccc}
\hline Values & Main beam & Floor beam & Stringer \\
\hline$\delta_{1}$ & 1.194 & 1.302 & 1.324 \\
$\delta_{2}$ & 1.000 & 1.000 & 1.000 \\
\hline
\end{tabular}


The operation stress range spectrums determined by Load Simulation Method are shown in Figure 5 .

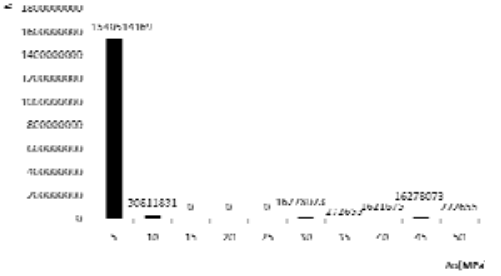

(a)Main beam

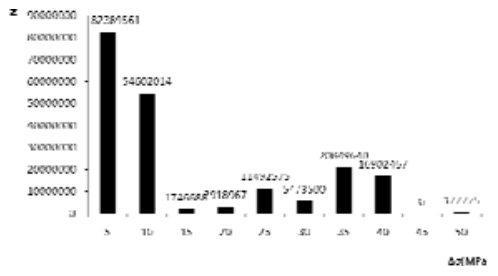

(b)Floorbeam

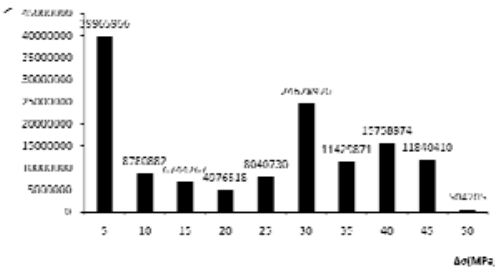

(c)Stringer

Figure 5. The Operation Stress Range Spectrums Determined by Load Simulation Method

The results of the fatigue accumulation damage and the remaining life of the bridge until 2011 are all listed in Table 5.

Table 5. Evaluation Results of Steel Plate Girder Bridge

\begin{tabular}{|c|c|c|c|c|}
\hline \multirow[b]{2}{*}{ Members } & \multicolumn{2}{|c|}{ Test Method } & \multicolumn{2}{|c|}{ Load Simulation Method } \\
\hline & Damage & $\begin{array}{l}\text { Remaining life } \\
\text { (Year) }\end{array}$ & Damage & $\begin{array}{c}\text { Remaining life } \\
\text { (Year) }\end{array}$ \\
\hline Main beam & 0.051 & 452 & 0.026 & 2220 \\
\hline Floor beam & 0.133 & 147 & 0.295 & 116 \\
\hline Stringer & 0.171 & 102 & 0.394 & 64 \\
\hline
\end{tabular}

From the results of two technical methods, the main beams and the floor beams are generally no fatigue problems. The remaining life of stringer in mid-span is about 64-102 years.

\section{EXAMPLE TWO: EVALUATION OF A STEEL TRUSS BRIDGE}

The second example is a riveted steel truss bridge which is on a single track railway. The bridge is $165 \mathrm{~m}$ long and composed of three simply supported steel girders with $55 \mathrm{~m}$ span .It was built in 1953 , and located in a railway trunk line. This length of the truss member was $5.5 \mathrm{~m}$, and the truss height was $8.5 \mathrm{~m}$. All members of the bridge were made up of angle steels and the steel plates.

The operation state of this bridge is good, whose scenery can be seen in Figure 6. Before1994, the traction engines were the steam locomotives, and from 1995 to 2009 the traction engines were the DF4 diesel locomotives. After completing the electrification improvement in 2010, the traction engines are SS3 or SS4 electric locomotives.

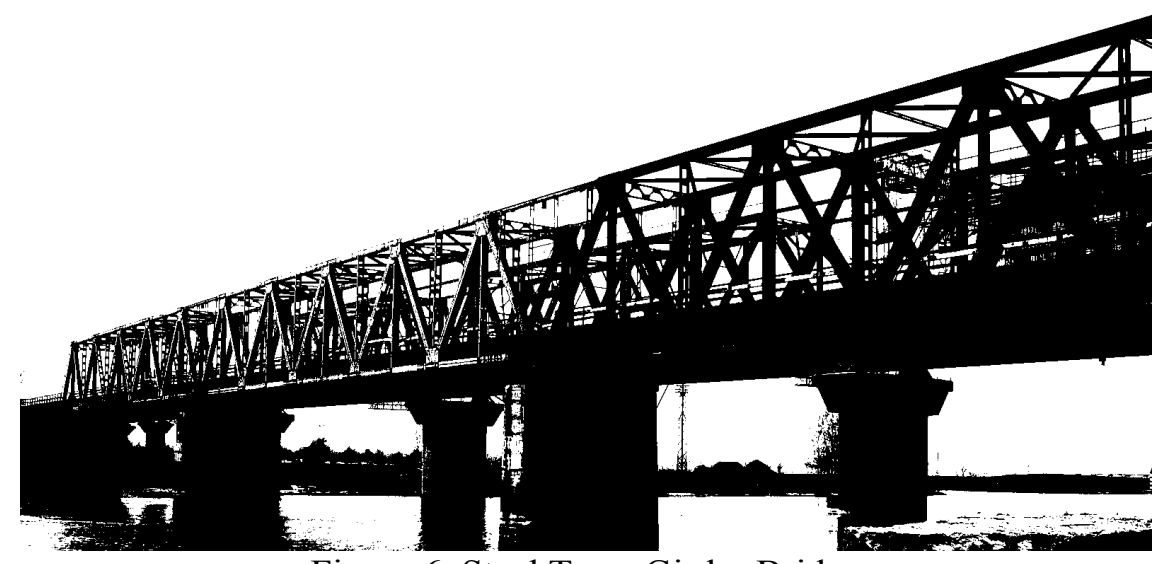

Figure 6. Steel Truss Girder Bridge 
Bottom chords, diagonals, hangers, floor beams and stringers are the critical members of this bridge for bearing the train load, so the strain gauges were placed at their sections. Their control details are all cross sections which were weaken by rivet holes. Same to the first example, the fatigue damage and the fatigue remaining life of this bridge will be evaluated by the two technical methods mentioned above. According to "Railway Bridge Examination Standard (2004)" [9], the S-N curves is $\lg N=13.14-3.5 \lg \Delta \sigma$.

The main adjustment factors of Test Method are given in Table 6. The value of $k_{1}$ is taken as 1.02 according to the test result of eccentricity. The value of $k_{2}$ can be determined by train formation during the service period. The strain gauges of the members were all placed in the gross section, so $k_{3}$ is the area ratio of gross and net section. Same to the first example, the influence of the locomotive and vehicle types is considered by directly correcting the stress history through referencing to pervious test before 1994 and by simulating calculation after 2010, so $k_{4}$ is taken as 1.0. Secondary stress needs to be considered in the truss members, and the values of $k_{5}$ are conservatively taken as 1.2 in bottom chords, diagonals and hangers. The influence of secondary stress can be ignored in floor beams and stringers, so their values of $k_{5}$ are taken as 1.0. The daily traffic volume in a month and the monthly traffic volume in a year are basically the same, so $\alpha_{1}$ and $\alpha_{2}$ are all taken as 1.0. The value of $\alpha_{3}$ can be determined by the past and the future traffic volume. The value of $\alpha_{4}$ is given in Table1.

Table 6. Values of Adjustment Factors in Test Method

\begin{tabular}{ccccccccc}
\hline \multirow{2}{*}{ Year } & Members & $k_{1}$ & $k_{2}$ & $k_{3}$ & $k_{5}$ & $\alpha_{2}$ & $\alpha_{3}$ & $\alpha_{4}$ \\
\hline \multirow{4}{*}{$1953-1971$} & Bottom chord & 1.02 & 1.005 & 1.306 & 1.200 & 1.000 & 0.280 & 0.570 \\
& Diagonal & 1.02 & 1.005 & 1.243 & 1.200 & 1.000 & 0.280 & 0.570 \\
& Hanger & 1.02 & 1.005 & 1.235 & 1.200 & 1.000 & 0.280 & 0.570 \\
& Floor beam & 1.02 & 1.005 & 1.197 & 1.000 & 1.000 & 0.280 & 0.570 \\
& Stringer & 1.02 & 1.005 & 1.236 & 1.000 & 1.000 & 0.280 & 0.570 \\
\hline & Bottom chord & 1.02 & 1.005 & 1.306 & 1.200 & 1.000 & 0.590 & 0.570 \\
$1972-1994$ & Diagonal & 1.02 & 1.005 & 1.243 & 1.200 & 1.000 & 0.590 & 0.570 \\
& Hanger & 1.02 & 1.005 & 1.235 & 1.200 & 1.000 & 0.590 & 0.570 \\
& Floor beam & 1.02 & 1.005 & 1.197 & 1.000 & 1.000 & 0.590 & 0.570 \\
& Stringer & 1.02 & 1.005 & 1.236 & 1.000 & 1.000 & 0.590 & 0.570 \\
\hline \multirow{4}{*}{ 1995-2009 } & Bottom chord & 1.02 & 1.005 & 1.306 & 1.200 & 1.000 & 1.000 & 1.000 \\
& Diagonal & 1.02 & 1.005 & 1.243 & 1.200 & 1.000 & 1.000 & 1.000 \\
& Hanger & 1.02 & 1.005 & 1.235 & 1.200 & 1.000 & 1.000 & 1.000 \\
& Floor beam & 1.02 & 1.005 & 1.197 & 1.000 & 1.000 & 1.000 & 1.000 \\
& Stringer & 1.02 & 1.005 & 1.236 & 1.000 & 1.000 & 1.000 & 1.000 \\
\hline \multirow{4}{*}{$2010-$} & Bottom chord & 1.02 & 1.005 & 1.306 & 1.200 & 1.000 & 1.450 & 1.430 \\
& Diagonal & 1.02 & 1.005 & 1.243 & 1.200 & 1.000 & 1.450 & 1.430 \\
& Hanger & 1.02 & 1.005 & 1.235 & 1.200 & 1.000 & 1.450 & 1.430 \\
& Floor beam & 1.02 & 1.005 & 1.197 & 1.000 & 1.000 & 1.450 & 1.430 \\
& Stringer & 1.02 & 1.005 & 1.236 & 1.000 & 1.000 & 1.450 & 1.430 \\
\hline
\end{tabular}

The operation stress range spectrums determined by Test Method are shown in Figure 7. 


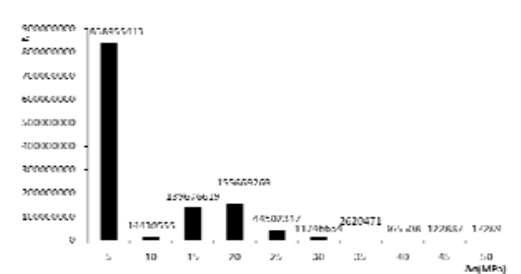

(a)Bottom chord

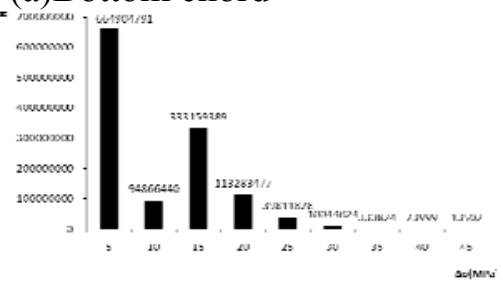

(d)Floorbeam

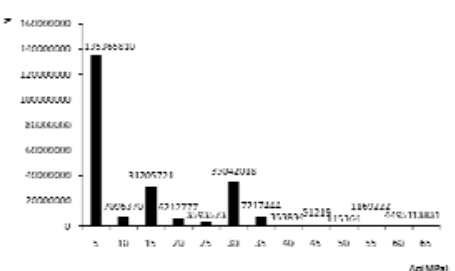

(b)Diagonal

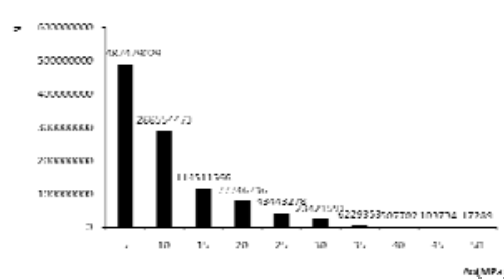

(c) Hanger

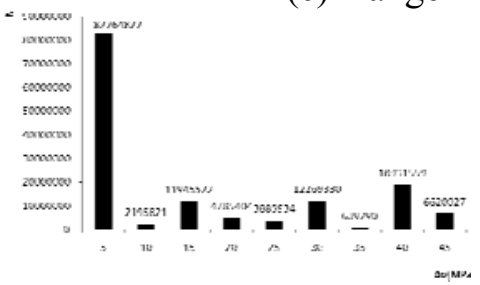

(e)Stringer

Figure 7. The Operation Stress Range Spectrums Determined by Test Method

The typical operation trains of Load Simulation Method are listed in Table 7. Values of $\delta_{1}$ and $\delta_{2}$ are given in Table 8. Same to the steel plate girder bridge, the value of $\delta_{1}$ can be calculated according the formula given. The random arrangement of the vehicles in a train can be ignored in the bridge, so $\delta_{2}$ also is taken as 1.0.

Table 7. Typical Operation Trains of Load Simulation Method

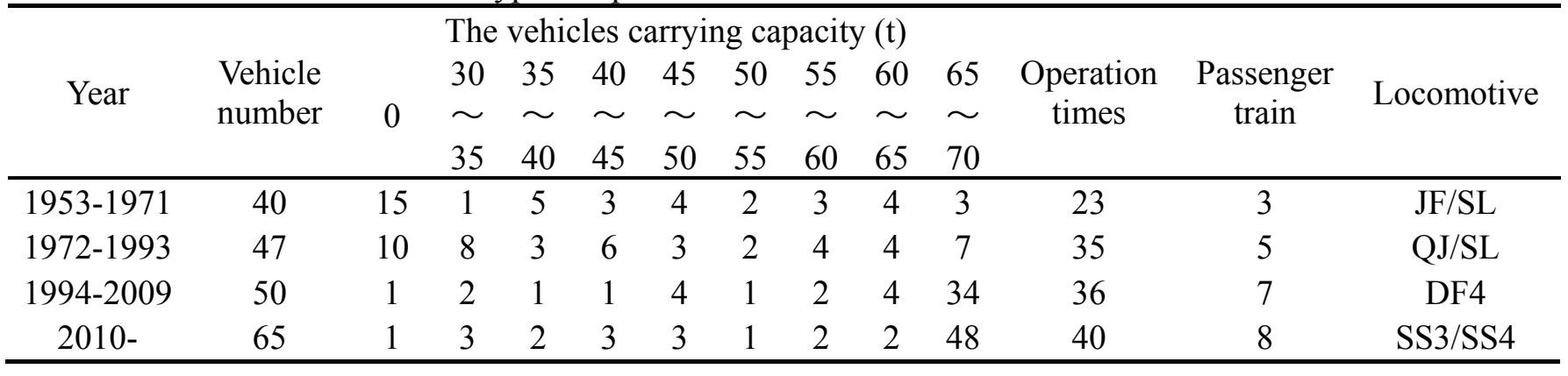

Table 8 Values of $\delta_{1}$ and $\delta_{2}$

\begin{tabular}{cccccc}
\hline Values & Bottom chord & Diagonal & Hanger & Floor beam & Stringer \\
\hline$\delta_{1}$ & 1.147 & 1.147 & 1.274 & 1.274 & 1.307 \\
$\delta_{2}$ & 1.000 & 1.000 & 1.000 & 1.000 & 1.000 \\
\hline
\end{tabular}

The operation stress range spectrums determined by Load Simulation Method are shown in Figure 8 .

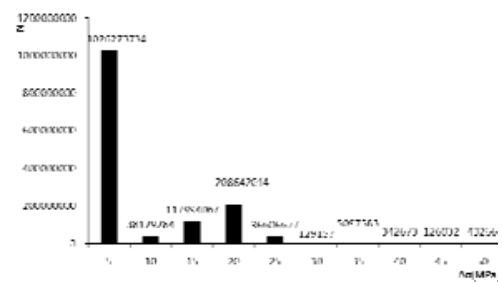

(a) Bottom Chord

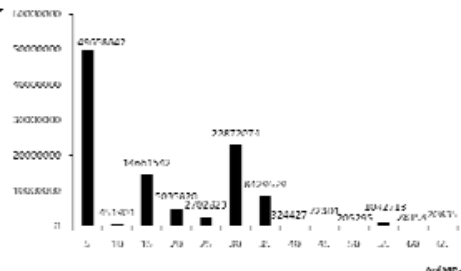

(b) Diagonal

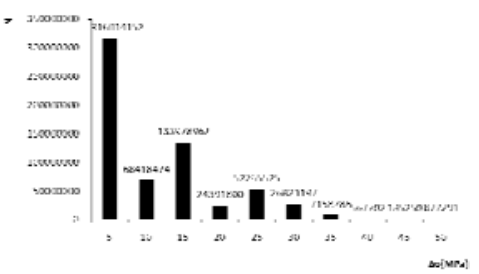

(c) Hanger 


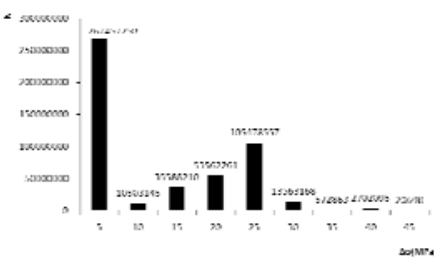

(d) Floor Beam

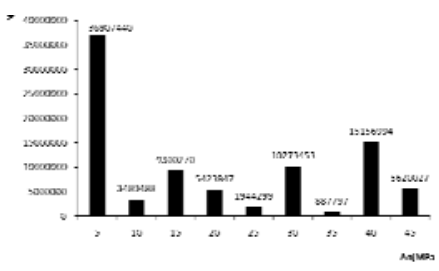

(e) Stringer

Figure 8 . The operation stress range spectrums determined by Load Simulation Method

The results of the fatigue accumulation damage and the remaining life of this bridge are listed in Table 9.

Table 9. Evaluation Result of Steel Truss Bridge

\begin{tabular}{|c|c|c|c|c|}
\hline \multirow[b]{2}{*}{ Members } & \multicolumn{2}{|c|}{ Test Method } & \multicolumn{2}{|c|}{ Load Simulation Method } \\
\hline & Damage & $\begin{array}{l}\text { Remaining } \\
\text { life(Year) }\end{array}$ & Damage & $\begin{array}{c}\text { Remaining } \\
\text { life(Year) }\end{array}$ \\
\hline Bottom chord & 0.205 & 125 & 0.160 & 197 \\
\hline Diagonal & 0.115 & 378 & 0.127 & 241 \\
\hline Hanger & 0.182 & 167 & 0.175 & 196 \\
\hline Floor beam & 0.077 & 445 & 0.102 & 210 \\
\hline Stringer & 0.593 & 33 & 0.413 & 37 \\
\hline
\end{tabular}

From the results of two technical methods, it is generally no fatigue problem in the bottom chord, the diagonal, the hanger, and the floor beam. The remaining life of stringer in mid-span is about 30 years.

\section{COMPARISON OF THE TWO TECHNICAL METHODS}

Through the fatigue life evaluation processes of two examples, the specifically differences of the two technical methods for determining the operation stress range spectrum are listed below.

(1)In Test Method, the eccentricity of vertical load and the special heavy train influence have been considered with $k_{1}$ and $k_{2}$, but in Load Simulation Method, these two influences have not been considered.

(2)The specific structural influence is considered with $k_{3}$ and $k_{5}$ in Test Method, however, it is directly considered in the bridge model in Load Simulation Method.

(3)The change of locomotive and vehicle types in Test Method is considered with $k_{4}$, but in Load Simulation Method, it is directly reflected in the stress history by the change of the locomotives and the vehicles of the typical train. Since it is quite cursory to only using $k_{4}$ in Test Method, it is often directly reflected in the stress history by referencing to pervious test or simulating calculation.

(4)The traffic volume change is reflected in two technical ways. It is corrected by $\alpha_{1}, \alpha_{2}$ and $\alpha_{3}$ in Test Method, and is adjusted by the typical train carrying capacity and the vehicle numbers in Load Simulation Method.

(5)Regarding the quantity change of hauling vehicles, Test Method is corrected by $\alpha_{4}$ which 
change with the locomotive traction gross weight. But in the actual operation, locomotive traction gross weight may not truly reflect the quantity change of hauling vehicles. Load Simulation Method is adjusted by the vehicle number of the typical train, which is obtained by the weighting average of vehicle numbers of actual trains, so it is closer to reality.

\section{CONCLUSIONS}

Through the analysis above, it can be concluded that two technical methods for estimating the operation stress range spectrum in the bridge service condition have characteristics as follows:

(1) From the point view of present analysis data, the main advantage of Test Method is the direct use of test data. The actual load effects can be considered in Test Method, such as dynamic effect, acceleration effect, etc. But Load Simulation Method is difficult to consider actual load effects by numerical simulation analysis. From this point of view, Test Method is closer to reality.

(2)From the point view of entire structure fatigue evaluation, Test Method is to calculate the fatigue performance of the detail based on the test data of the measurement position. The deviation of selecting the test position will affect the overall assessment of the fatigue life of the structure. But Load Simulation Method can be used to calculate the fatigue stress history of any position of the structure, thus avoiding potential limitation of Test Method.

(3) From the point view of working condition, statistics workloads of Test Method are relatively small, but this method needs on-site test, so it is applicable to the bridge with better test conditions. Load Simulation Method avoids the site test tasks, but is based on adequate statistical information and large amount of calculation. The calculation steps are also relatively complex.

\section{RECOMMENDATIONS}

Through the above assessment practices and the characteristics analysis of the two technical methods, in order to improve the assessment accuracy, the following works need to be carried out in future.

(1) The operation stress spectrum is the key factor to the entire evaluation. Regardless of Test Method or Load Simulation Method, both need the complete material or data are needed to obtain more accurate result. Therefore, the existing bridge material database needs to be established, including design material, general vehicles, all previous years traffic volume and so on.

(2) The S-N curve for carrying out the evaluation often uses the experiment of the new material, which cannot consider the material quality of the old bridge and the characteristic deterioration along with the time. Their influence on the fatigue requires to be studied.

(3) Two technical methods are both based on the Palmgren-Miner rule. For this rule itself, there are also many questions need to be studied, such as whether the load order affects the fatigue damage or not, if the stress which is lower than the fatigue cut-off limit induces the fatigue damage, as well as the criteria of cut off limit, and so on. 


\section{REFERENCES}

[1] The Statistics Centre of China Railway Ministry, "National Railway Statistics Abstract in 2010”, China Railway Publishing House, Beijing, 2012. (in Chinese)

[2] Liu, X.G., Zhang, Y.L. and Zhao, X.X., "Key Technologies of Existing Railway Steel Bridge of Adapting Heavy Transport", Research Report TY- 3225, China Academy Of Railway Sciences, Beijing, 2011. ( in Chinese)

[3] Sharifi, Y., "Uniform Corrosion Wastage Effects on the Load-carrying Capacity of Damaged Steel Beams", Advanced Steel Construction, 2012, Vol. 8, No. 2, pp. 153-167.

[4] Pan, J.Y., "Reliability Theory of Fatigue in Design of Railway Steel Bridges", Steel Construction, 1995, Vol. 10, No. 27, pp. 1-8. (in Chinese)

[5] Pan, J.Y., "Railway Steel Bridge Design", Railway Construction Technology, 2009, Vol. 10, No. 27, pp. 1-9. (in Chinese)

[6] Shi, Y.G., Yang, Y.M., Li, Z.R., Shi, Z.Q. and Hou, W.W., "Remaining Life Evaluation of Old Riveted Steel Railway Bridge", China Academy of Railway Science, 1994, Vol. 15, No. 1, pp. 66-81. (in Chinese)

[7] Shi, Y.J., "Remaining Life Evaluation of 'Old Riveted' Steel Railway Bridge", Railway Engineering, 1995, Vol. 12, No. 2, pp. 44-76. (in Chinese)

[8] China Railway Ministry, "Code for Design on Steel Structure of Railway Bridge" TB10002.2-2005, China Railway Publishing House, Beijing, 2005. (in Chinese)

[9] China Railway Ministry, "Railway Bridge Examination Standard (2004)", China Railway Publishing House, Beijing, 2004. (in Chinese) 